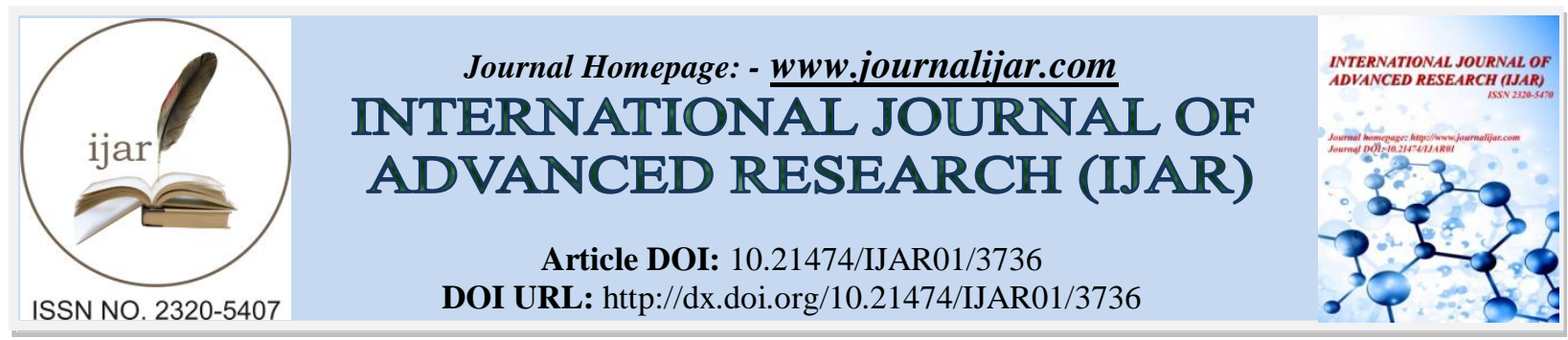

RESEARCH ARTICLE

\title{
PREDICTION OF RESPONSE TO PEGYLATED INTERFERON PLUS RIBAVIRIN IN HEPATITIS C PATIENTS BY IL28B VARIATION AND ITS RELATION TO OTHER DIFFERENT PREDICTORS.
}

\section{Noran Atef Elkordy ${ }^{1}$, Ahmed Yamani Sayed ${ }^{2}$, Dina Sabry Abd Elfatah ${ }^{3}$, Mona Ahmed Amin ${ }^{4}$, Ali Hassan Farag $^{2}$ and Dina Abd Elhakeem Elgendy ${ }^{4}$.}

1. Corresponding author: Assistant lecturer of internal medicine, Kasr Alainy, Cairo University.

2. Lecturer of internal medicine, Kasr Alainy, Cairo University.

3. Prof. of biochemistry, Kasr Alainy, Cairo University.

4. Prof. of internal medicine, Kasr Alainy, Cairo University.

\section{Manuscript Info}

Manuscript History

Received: 15 January 2017

Final Accepted: 12 February 2017

Published: March 2017

Key words:-

$\mathrm{HCV}$, Ribavirin, Pegylated- Interferon, IL28B

\section{Abstract}

Worldwide, hepatitis C Virus (HCV) is recognized as a major threat to global public health. Accurately predicting the patients who will respond to therapy of $\mathrm{HCV}$ by interferon and ribavirin is still important, for patient care and also with respect to the cost as new DAAs are not always available. Studies have shown that IL28B is strongly associated with the response to treatment of hepatitis $\mathrm{C}$ by interferon and ribavirin. Our patients are 200 divided into two equal groups, responders and non- responders to Interferon ribavirin treatment. They are submitted to detailed history and clinical examination including body mass index calculation, laboratory examination: CBC, PT, PC, serum Albumin, AST, ALT, Bilirubin total, viral load by PCR , abdominal ultrasound , liver biopsy, IL28B gene. We proved that IL28B is the strongest predictor of response of treatment by Peg/interferon ribavirin and CC allele has the best chance to respond to treatment. Also, BMI, ALT and ALP could be used as predictors for response.

Copy Right, IJAR, 2017,. All rights reserved.

\section{Introduction:-}

Hepatitis C virus (HCV) infection is a major cause of chronic liver disease (Berg T et al., 2003). About 2.35\% of the world's population is infected with HCV (Lavanchy D, 2011).

In Egypt, hepatitis C virus (HCV) has the largest epidemic in the world. The released Egyptian Demographic Health Survey [EDHS] declared that the overall prevalence of HCV is $14.7 \%$ (El-Zanaty F and Way A, 2009). The blood borne virus, which is highly infectious, kills an estimated 40000 Egyptians a year and at least 1 in 10 of the population aged 15 to 59 is infected (Henk B, 2014).

Studies have shown that the prevalence of antibodies to HCV (anti-HCV) specially, to a single subtype, 4a in Egypt is approximately 10-fold greater than in the United States and Europe (Strickland GT et al., 2002). Clinical trials demonstrated that type 4 response to treatment by Pegylated- Interferon (PEG- INT) and ribavirin is better than type 1 response but it is worse than type 2 and 3 response (Martinot-Peignoux M et al., 2010).

Corresponding Author:- Noran Atef Elkordy.

Address:- Corresponding author: Assistant lecturer of internal medicine, Kasr Alainy, Cairo University. 
Accurately predicting the patients who will respond to therapy is becoming increasingly important, both from the point of patient care and also with respect to the healthcare cost as clinicians need to continue treatment in patients who will respond and stop treatment in patients who are unlikely to respond and use new protease inhibitors instead of Peg- interferon and ribavirin (Zeuzem S et al., 2004). Also in era of new direct antivirals, as they are not always available.

Older age, advanced stage of fibrosis, African-American ethnicity and HCV- related factors, including HCV genotype 1 and high viral load at baseline, predict poor response to anti-viral therapy. Furthermore, metabolic factors, such as high body mass index (BMI), presence and severity of liver steatosis and increasing homeostasis model assessment of insulin resistance (HOMA-IR) score have been reported as negative predictors of response (Bressler BL et al., 2003).

On the other hand, early on-treatment kinetics of HCV RNA, e.g. undetectable HCV RNA at week 4, has a high positive predictive value of SVR (Yu ML et al., 2008). Several independent studies have consistently shown that single nucleotide polymorphisms (SNPs) near IL28B, which encodes the type III interferon are strongly associated with the response to treatment of chronic hepatitis C (Ge D et al., 2009).

However, very few studies are available where all these novel pre- treatment variables are analyzed together in multivariate models.

The aim of this study was to find if there is a relation between IL28B gene single nucleotide polymorphism and the response to treatment of $\mathrm{HCV}$ by combination of PEG- Interferon and ribavirin. Also, to find if IL28B was a surrogate predictor of the response to $\mathrm{HCV}$ treatment compared to other predicting factors like age, sex, liver enzymes, liver biopsy and degree of steatosis, body mass index (BMI) and viral load.

\section{Material and Methods:- \\ Study population:-}

A prospective study was conducted on 200 patients, including 124 males and 76 females \&the mean age was (41.93+9.686) years taken from 657 patients after they took pegylated-interferon/ ribavirin. They were recruited from the outpatient clinics of the Internal Medicine department, Kasr Al Aini hospital, Cairo University, Beni-Suef Public Hospital and National liver institute from 2012 to 2014, while patients with Co- infection with HBV and were receiving immunosuppressant drugs, chemotherapy or corticosteroids concomitantly with the study were excluded. Following the response to treatment with PEG interferon and ribavirin after 48 weeks, the patients were classified into two groups, responders and non- responders each group contained 100 patients. The study protocol conformed to the ethical guidelines of 1975 the Helinsi'ci declaration and was approved by the ethical committee of internal medicine, faculty of medicine, Cairo University. Written informed consents were obtained from participants in this study.

\section{Blood collection and sample preparation:-}

Blood $(10 \mathrm{ml})$ was withdrawn by venipuncture; After analyzing cell blood counts (CBC) on aliquots of whole blood in EDTA tube $(2 \mathrm{ml})$ using the (sysmex corp, Kope, Japan) automated hematology analyzer. Liver function tests (bilirubin, ALT, AST, ALP, albumin, PT, PC, \& INR), urea and creatinine were measured. Viral load by PCR DNA extraction. DNA was extracted from mononuclear cell layer of whole blood sample using QIAamp kit supplied by Qiagen (USA) according to manufacturer's specifications. IL28B genotyping (rs12979860) was carried out by means of custom TaqMan Assay (Applied Biosystem, USA) designed to detect the following SNP: rs12979860. Primers and probes sequence as following; rs12979860 (5'-GCTTATCGCATACGGCTAGG-3', sense) and rs12979860 (5'-AGGCTCAGGGTCAATCACAG-3', antisense). The TaqMan minor groove binder probe sequences were VIC 5'- ACCTGCCTACCCTT G-3', and FAM 5'- CTGCCCACC CTTG-3'. The detection was carried out by qPCR in a StepOne thermocycler by using fluorescent probes. The amplification conditions were as follows: After a denaturation time of $10 \mathrm{~min}$ at $96^{\circ} \mathrm{C}, 45$ cycles of $92^{\circ} \mathrm{C} 15 \mathrm{sec} 60^{\circ} \mathrm{C} 90 \mathrm{sec}$ were carried out and fluorescence was measured at the end of every cycle and at endpoint. All samples were determined by dublicate and genotypes were assigned both, by the gene identification software (StepOne 2.0, Applied Biosystem) and by analysis of the reference cycle number for each fluorescence curve, calculated by the use of algorithm (Applied Biosystem). 


\section{Statistical analysis:-}

Pre-coded data was entered into the computer program SPSS (Statistical Package for the Social Science; SPSS Inc., Chicago, IL, USA) release 15 for Microsoft Windows (2006) to be statistically analyzed. Data was summarized using mean and standard deviation for quantitative variables and frequency and percentage for qualitative ones. Comparison of numerical variables between the study groups was done using Student $t$ test for independent samples while comparing categorical data was done using Chi square $\left(\chi^{2}\right)$ test. Exact test was used instead when the expected frequency is less than 5. Univariate and multivariate analysis models were used to test for the preferential effect of the independent variable(s) on response to treatment. $p$ values less than 0.05 was considered statistically significant.

\section{Results:-}

Two hundred patients were included in our study. The demographic characteristics and laboratory results are shown in (table 1).

Table 1:- Univariate analysis. HS: highly significant S: significant N S: non- significant

\begin{tabular}{|c|c|c|c|c|}
\hline \multicolumn{2}{|l|}{ Variables } & Non responder & Responder & P value \\
\hline \multicolumn{2}{|l|}{ Number } & 100 & 100 & \\
\hline \multicolumn{2}{|c|}{ Age(yrs.) (Mean \pm SD) } & $44.42 \pm 9.111$ & $39.44 \pm 9.647$ & $0.000(\mathrm{HS})$ \\
\hline \multirow{2}{*}{ Sex } & Male $(\mathrm{N}, \%)$ & $52(53.1 \%)$ & $30(30 \%)$ & \multirow[t]{2}{*}{$0.14(\mathrm{NS})$} \\
\hline & Female $(\mathrm{N}, \%)$ & $48(46.9 \%)$ & $70(70 \%)$ & \\
\hline \multicolumn{2}{|c|}{ BMI $(\%)($ Mean \pm SD) } & $29.5260 \pm 5.15565$ & $26.3260 \pm 3.39585$ & $0.000(\mathrm{HS})$ \\
\hline \multicolumn{2}{|c|}{ AST(IU/L) } & $64.99 \pm 41.528$ & $27.44 \pm 16.469$ & $0.000(\mathrm{HS})$ \\
\hline \multicolumn{2}{|l|}{ ALT (IU/L) } & $69.71 \pm 40.743$ & $25.46 \pm 14.206$ & $0.000(\mathrm{HS})$ \\
\hline \multicolumn{2}{|l|}{ ALP(IU/L) } & $120.41 \pm 62.545$ & $156.17 \pm 52.245$ & $0.000(\mathrm{HS})$ \\
\hline \multicolumn{2}{|c|}{ Viral load (before treatment) } & $1,752,561.87 \pm 8,147,842.224$ & $742,197.40 \pm 1,641,246.876$ & $0.226(\mathrm{NS})$ \\
\hline \multirow[t]{3}{*}{ II28b SNP } & $\mathrm{CC}(\mathrm{N}, \%)$ & $6(6 \%)$ & $47(47 \%)$ & \multirow{3}{*}{$0.000(\mathrm{HS})$} \\
\hline & $\mathrm{CT}(\mathrm{N}, \%)$ & $60(60 \%)$ & $47(47 \%)$ & \\
\hline & $\mathrm{TT}(\mathrm{N}, \%)$ & $34(34 \%)$ & $6(6 \%)$ & \\
\hline \multirow[t]{5}{*}{ Fibrosis } & 0 grade $(\mathrm{N}, \%)$ & $10(10 \%)$ & $4(4 \%)$ & \multirow[t]{5}{*}{$0.29(\mathrm{NS})$} \\
\hline & 1 grade $(\mathrm{N}, \%)$ & $59(.59 \%)$ & $76(76 \%)$ & \\
\hline & 2 grade $(\mathrm{N}, \%)$ & $21(21 \%)$ & $14(14 \%)$ & \\
\hline & 3 grade $(\mathrm{N}, \%)$ & $7(7 \%)$ & $6(6 \%)$ & \\
\hline & 4 grade $(\mathrm{N}, \%)$ & $3(3 \%)$ & $0(0 \%)$ & \\
\hline
\end{tabular}

By using univariate analysis, the results demonstrate a highly significant relation between age, sex of the patient and the response to treatment of HCV by PEG interferon and ribavirin. The p value was respectively (0.00 \&0.014). Also the study shows significant relation between treatment response and elevated ALT \& ALP of the patients. The study reported that a highly significant relation between IL28B subtype and the response to treatment of HCV by PEG interferon and ribavirin. CC showed more incidence to respond to treatment and TT less incidence to respond. In group of responders (CC/CT/TT) represented $(47 \% / 47 \% / 6 \%)$ respectively. In non- responders group (CC/CT/TT) represented $(6 \% / 60 \% / 34 \%)$ respectively. The $\mathrm{P}$ value was $(0.000)$. However, regarding both viral load \& fibrosis grades, no significant relation between those \&the response to treatment of HCV by PEG interferon and ribavirin ( $p$ value $=0.226 \& 0,092)$ respectively.

By multivariate analysis: The present study illustrated a significant relation between BMI and the response to treatment, the lesser the BMI is, the better response to treatment $(\mathrm{p}=0.005)$. The $\mathrm{p}$ value for the ALT, ALP and its relation to response to treatment were $(0.000,0.028)$ respectively. As well as the $\mathrm{p}$ value for the IL28B subtype and its relation to response to treatment was $(0.000)$ in multivariate analysis. These result showed highly significant relation between IL28B subtype and the response to treatment. CC subtype has more incidence to respond to treatment by PEG interferon and ribavirin. TT subtype has less incidence to respond to treatment by PEG interferon and ribavirin. The odd ratio for BMI, ALT, ALP and IL28B 0.76, 0.92, 0.01 and 8.79 respectively. On the other hand, no significant relation between the response to treatment of HCV by PEG interferon and ribavirin and each of these factors including age, sex. AST, viral load \& fibrosis $(\mathrm{p}$ value $=0.405,0.851,0.051,0.531 \& 0.405$ respectively) in multivariate analysis. 


\section{Discussion:-}

Many studies were done to find predictors of treatment response to INF and ribavirin in HCV. Finding those patients who will mostly respond to treatment will help in decreasing the cost and side effects of medications. Moreover, this will help in choosing patients to use the triple therapy with direct acting antiviral drugs (Butti M, 2002). An important factor influencing treatment outcome in chronic hepatitis C has been discovered IL28B gene polymorphism that is also distributed according to ethnic and geographical areas. The CC allele polymorphism occurs in $33 \%$ of Americans of European ancestry, 14\% of African Americans and 29\% of Hispanic Americans (Thomas DL et al., 2009). Individuals carrying IL28B polymorphism with CC alleles have the best prognosis, with two to three times the rate of sustained virological response (SVR) with IFN-based anti-HCV therapy, while those with TT alleles have the worst SVR rates (Thompson AJ et al., 2010). Most of the initial studies of this polymorphism were conducted on genotype 1 patients. However, a study by Asselah T, et al., (2012) has shown that, in patients with HCV genotype 4, patients with CC, CT and TT genotypes have $82 \%, 47 \%$ and $29 \%$ SVR rates respectively.

IL28B genotype is the most important pretreatment predictor of response to peg-IFN and RBV therapy for HCV-1. Patients who carry the good response genotype (e.g. C/C at rs12979860) have reported SVR rates $\geq 70 \%$, a two- to threefold increase over patients who carry one of the poor response genotypes (e.g. C/T, T/T at rs12979860) (Chen $\mathrm{Y}$ et al., 2012). While in genotype 2 and 3 infected patients, this association seems to be less pronounced (Scherzer TM et al., 2011).

The primary goal of the present study was to evaluate the variable predictors of treatment response (PEG interferon and ribavirin ) in Egyptian patients infected with HCV subtypes 4a, mainly age , sex, BMI, fibrosis on liver biopsy, viral load, AST, ALT, ALP and IL28B SNP.

For HCV genotype 4 (HCV-4), three studies on HCV mono-infected (Stättermayer AF et al., 2011; De Nicola S et al., 2012; Asselah T et al., 2012) and two in patients coinfected with HCV and the human immunodeficiency virus (HIV) (Pineda JA et al., 2010; Rallón NI et al., 2011) suggest that single nucleotide polymorphisms (SNP) near IL28B are strong predictors of treatment outcome.

The current study was conducted on 200 Egyptian patients infected by HCV; 124 males and 76 females. The patients were classified into two groups; responders and non-responders according to response to treatment with PEG interferon and ribavirin following 48 weeks. Univariate and multivariate analysis were used to detect the relation between different predictors and the response to treatment by c. We studied the age, sex, BMI, fibrosis on liver biopsy, viral load, AST, ALT, ALP and IL28B SNP as predictors of response. Our results showed a highly significant relation between IL28B subtype and the response to treatment of HCV by PEG interferon and ribavirin in univariate analysis. $\mathrm{CC}$ subtype showed more incidence to respond to treatment and TT less incidence to respond. In group of responders $(\mathrm{CC} / \mathrm{CT} / \mathrm{TT})$ represented $(47 \% / 47 \% / 6 \%)$ respectively. In non- responders group (CC/CT/TT) represented $(6 \% / 60 \% / 34 \%)$ respectively. The $\mathrm{P}$ value was $(0.000)$. The $\mathrm{p}$ value for the IL28B subtype and its relation to response to treatment was $(0.000)$ in multivariate analysis. These result showed highly significant relation between IL28B subtype and the response to treatment. CC subtype has more incidence to respond to treatment by PEG interferon and ribavirin. TT subtype has fewer incidences to respond to treatment by PEG interferon and ribavirin. These results are in accordance with Stättermayer AF, et al., (2011); De Nicola S, et al., (2012); Asselah T et al., (2012).

In our study, we found that the age has a highly significant relation to the response to treatment of HCV by PEG interferon and ribavirin in univariate analysis. The responders mean age mean is 39.44 and the lesser the age, the better the response with a $\mathrm{p}$ value (0.000). However, this relation was not detected in multivariate analysis. The $\mathrm{p}$ value for the age and its relation to response to treatment in multivariate analysis was (0.567). These results showed no significant relation between age and the response to treatment of HCV by PEG interferon and ribavirin. The SVR was found significantly higher in patients below 40 years of age compared to those above 40 years $(P=0.022)$ in a study done by Muhammad Idrees and Sheikh Riazuddin, (2009) and this was disagreed by Gamal El Din E, et al., (2010) found no relation between age and response to treatment by Peg/ribavirin.

Strangely, in our study, the fibrosis stage did not show significant relation to SVR neither in univariate or multivariate analysis ( $\mathrm{p}$ value $=0.050$ and $=0.851$, respectively). Only in one study by Thomas Berg et al., (2003), the stage of fibrosis was not significantly associated with SVR. 
We found a better response to treatment with PEG and ribavirin in males compared to females. The $p$ value of the sex and its relation to response to treatment was $(0.014)$ in favor of the male sex. However, in multivariate analysis this effect disappeared. The $p$ value of the sex and its relation to response to treatment was $(0.405)$. These results showed no significant relation between sex and the response to treatment of HCV by PEG interferon and ribavirin. While, Hadziyannis et al., (2004) and Conjeevaram et al., (2006) found that males have a lower SVR than do females, no statistically significant correlation was found between sex and SVR by Kau A et al., (2008).

In our study, a highly significant relation was found between BMI of the patient and the response to treatment of HCV by PEG interferon and ribavirin. The $P$ value was $(0.000)$ in univariate analysis. The $p$ value was $(0.005)$ in multivariate analysis in our study. These results showed highly significant relation between BMI and the response to treatment. Bressler BL et al., (2003), reported that body fat mass, as estimated by body mass index (BMI), influenced viral eradication in response to antiviral treatment for HCV and found that obesity defined as a BMI greater than 30 was a negative predictor of response to HCV treatment. Body weight was not significantly associated with SVR in a study done by Thomas Berg et al, (2003).

Our results univariate analysis showed a highly significant relation between AST of the patient and the response to treatment of HCV by PEG interferon and ribavirin as the P value was (0.000). While the p value for the AST and its relation to response to treatment was $(0.051)$ in multivariate analysis, which showed no relation between AST and the response to treatment of HCV by PEG interferon and ribavirin. Other studies showed mixed results. In a study done by AS Hgar $\mathrm{H}$ et al., (2009), they found the lesser AST was, the better the response to Peg/ribavirin. Gamal El Din E et al., (2010) found no relation between AST level and SVR.

Our results showed a highly significant relation between ALT of the patient and the response to treatment of HCV by PEG interferon and ribavirin in univariate analysis. The $\mathrm{P}$ value was $(0.000)$. The $\mathrm{p}$ value for the ALT and its relation to response to treatment was (0.000) in multivariate analysis. These result showed highly significant relation between ALT and the response to treatment. The lesser the ALT is, the better the response to treatment. The mean for responders was 25.46. The studied baseline ALT levels, which were an indicator of liver damage, were significantly higher in responder patients than in non-responders in treatment $(\mathrm{p}=0.002)$ (Berg T et al., 2003). Pretreatment ALT levels had no predictive role in treatment response rate in study done by Muhammad Idrees and Sheikh Riazuddin, (2009).

Our results showed a highly significant relation between ALP of the patient and the response to treatment of HCV by PEG interferon and ribavirin in univariate analysis. The $\mathrm{P}$ value was $(0.000)$. The mean for responders was 156.17units/litter. The higher the ALP is, the better the response. The $\mathrm{p}$ value for the ALP and its relation to response to treatment was (0.028) in multivariate analysis in our study. These results showed significant relation between ALP and the response to treatment. ALP was of no significant impact in a study done by Gamal El Din E et al., (2010). In a study done by Ekram W et al., (2015); they reported a significantly higher in alkaline phosphatase, in non-responder group than in responder group at baseline assessment $(\mathrm{p}=0.037)$.

In our study the $p$ value for the viral load and its relation to response to treatment was $(0.226)$ in univariate analysis. These result showed no significant relation between viral load and the response to treatment of HCV by PEG interferon and ribavirin. The $\mathrm{p}$ value for the viral load and its relation to response to treatment was $(0.531)$ in multivariate analysis in our study. These result showed no significant relation between viral load and the response to treatment of HCV by PEG interferon and ribavirin. A low baseline viral load $(\mathrm{P}=0.04)$ was independent predictor for sustained virologic response in a study done by Thomas Berg et al., (2003). The predictive effect of baseline viral load was confirmed by several studies, even in the studies of patients co-infected with HCV and HIV (Zeuzem S et al., 2012).

\section{Conclusion:-}

We concluded that IL28B is the strongest independent predictor of response of treatment by Peg/ ribavirin by the highest OR 8.79. Also, BMI, ALT and ALP could be used as predictors for response.

AST, age, sex, viral load and fibrosis are not predictors for response according to our study. 


\section{Acknowledgement:-}

First, and foremost, all thanks and gratitude to God, most gracious and most merciful.

I would like to express my deepest gratitude and thanks to Prof. Dr. Dina El Gendy, Professor of Internal medicine, Cairo University, for her continuous guidance and valuable advice for enriching this work. I appreciate her great support for me, which has given me a powerful push helping this study to be established.

I am extremely grateful to Dr. Ali Farag, Lecturer of Internal medicine, Cairo University, for his continuous guidance and suggestions, saving no effort or time to make this work better.

I would like to express my highest appreciation to Dr. Dina Sabry, Prof. of medical biochemistry, Cairo University, for her cooperation, and assistance during the whole work.

I am extremely grateful to Dr. Mona Amin, Prof. of Internal medicine, Cairo University, for her cooperation, and assistance during the whole work.

\section{References:-}

1. AS Hgar $\mathrm{H}$ et al, Helmy $\mathrm{H}$,Khan M. Predictors of sustained virologic response at course of 48 week of treatment by PEG interferon alpha $2 \mathrm{a}$ and ribavirin in patients infected by HCV genotype 4 . Ann Saudi Med 2009; 29 (1):4-14.

2. Asselah T, De Muynck S, Broët P et al., IL28B polymorphism is associated with treatment response in patients with genotype 4 chronic hepatitis C. J Hepatol2012; 56: 527-532.

3. Berg T, Sarrazin C, Herrmann E, Hinrichsen H, Gerlach T, et al. (2003) Prediction of treatment outcome in patients with chronic hepatitis C: significance of baseline parameters and viral dynamics during therapy. Hepatology2003; 37(3): 600-609.

4. Bressler BL, Guindi M, Tomlinson G, Heathcote J. High body mass index is an independent risk factor for nonresponse to antiviral treatment in chronic Hepatitis C. Hepatology2003; 38: 639-644.

5. Butti M treatment de la hepatitis corinica c. Factors relacionados con la respuesta. GH continuada2002; 1: 2.

6. Chen Y, Xu HX, Wang LJ, Liu XX, Mahato RI, Zhao YR. Meta-analysis: IL28B polymorphisms predict sustained viral response in $\mathrm{HCV}$ patients treated with pegylated interferon-alpha and ribavirin. Aliment Pharmacol Ther2012; 36: 91-103.

7. Conjeevaram H.S., Fried M.W., Jeffers L.J., Terrault N.A., Wiley-Lucas T.E., Afdhal N. et al. (2006) Peginterferon and ribavirin treatment in African American and Caucasian American patients with hepatitis C genotype 1. Gastroenterology 2006; 131: 470-477.

8. De Nicola S, Aghemo A, Rumi MG et al. An IL28B polymorphism predicts pegylated interferon plus ribavirin treatment outcome in chronic hepatitis C genotype 4. Hepatology2012; 55: 336-342.

9. Ekram W. Abd El-Wahab, Ashraf Mikheal, Fathallah Sidkey and Hanan Z. Shatat. Insulin Resistance as a Predictor of Early Virologic Response to HCV Therapy Among Chronic HCV Egyptian Patients. Journal of Medical Virology2015; 87: 428-440.

10. El-Zanaty F, Way A. Egypt Demographic and Health Survey 2008. Egyptian: Ministry of Health. El-Zanaty and Associates, and Macro International. Cairo. p 431, 2009. Egypt Demographic Health Survey: Final Report June 2009.

11. Ge D, Fellay J, Thompson AJ, Simon JS, Shianna KV, Urban TJ, Heinzen EL, Qiu P, Bertelsen AH, Muir AJ, Sulkowski M, McHutchison JG, Goldstein DB: Genetic variation in IL28B predicts hepatitis C treatmentinduced viral clearance. Nature 2009; 461(7262): 399-401.

12. Gmal El Din Esmat Gamil, Maissa El Said El Raziky, Rabab Maamoun Salama, Wafaa Ahmed El Akel, Waleed Fouad Fathalah1, Dina Ismail Attia M. "Factors Associated with Rapid and Early Virologic Response to Peginterferon Alfa- 2a/Ribavirin Treatment in HCV Genotype 1 Patient's Representative of the General Chronic Hepatitis C Population,” Journal of Viral Hepatitis2010; Vol. 17, No. 2, pp. 139-147.

13. Hadziyannis SJ, Sette H Jr, Morgan TR, Balan V, Diago M, Marcellin P, et al., Peginterferon-alpha2a and ribavirin combination therapy in chronic hepatitis $\mathrm{C}$ : a randomized study of treatment duration and ribavirin dose. Ann Intern Med. Mar 2 2004; 140(5): 346-55.

14. Henk Bekedam, Egypt steps up efforts against hepatitis C WHO July 2014.

15. Kau A, Vermehren J, Sarrazin C. Treatment predictors of a sustained virologic response in hepatitis B and C. J. Hepatol. 2008; 49(4), 634-651.

16. Lavanchy D. Evolving epidemiology of hepatitis C virus. Clin Microbiol Infect 2011; 17: 107-115. 
17. Martinot-Peignoux M, Stern C, Maylin S, et al. Twelve weeks posttreatment follow-up is as relevant as 24 weeks to determine the sustained virologic response in patients with hepatitis $\mathrm{C}$ virus receiving pegylated interferon and ribavirin. Hepatology 2010; 51:1122-6.

18. Muhammad Idrees and Sheikh Riazuddin. A study of best positive predictors for sustained virologic response to interferon alpha plus ribavirin therapy in naive chronic hepatitis C patients. BMC Gastroenterology 2009; 9: 5.

19. Pineda JA, Caruz A, Rivero A et al., Prediction of response to pegylated interferon plus ribavirin by IL28B gene variation in patients coinfected with HIV and hepatitis C virus. Clin. Infect Dis2010; 51: 788-795.

20. Rallón NI, Soriano V, Naggie S et al., IL28B gene polymorphisms and viral kinetics in HIV/hepatitis C viruscoinfected patients treated with pegylated interferon and ribavirin. AIDS 2011; 25: 1025-1033.

21. Scherzer TM, Hofer H, Staettermayer AF et al., Early virologic response and IL28B polymorphisms in patients with chronic hepatitis $\mathrm{C}$ genotype 3 treated with peginterferon alfa-2a and ribavirin. J Hepatol 2011; 54: 866871.

22. Stättermayer AF, Stauber R, Hofer H et al., Impact of IL28B genotype on the early and sustained virologic response in treatment-naïve patients with chronic hepatitis C. Clin Gastroenterol Hepatol2011; 9: 344-350.

23. Strickland GT et al., 2002 Strickland GT, et al. 2002. Role of hepatitis C infection in chronic liver disease in Egypt. Am. J. Trop. Med. Hyg. 67:436-442.

24. Thomas DL, Thio CL, Martin MP et al., Genetic variation in IL28B and spontaneous clearance of hepatitis C virus.Nature2009; 461: 798-801.

25. Thompson AJ, Muir AJ, Sulkowski MS et al., Interleukin-28B polymorphism improves viral kinetics and is the strongest pretreatment predictor of sustained virologic response in genotype 1 hepatitis $\mathrm{C}$ virus. Gastroenterology2010; 139: 120-129.

26. Yu ML, 2008 23. Yu ML et al. (2008) Rapid virological response and treatment duration for chronic hepatitis C genotype 1 patients: a randomized trial. Hepatology 47: 1884-1893.

27. Zeuzem S, Hultcrantz R, Bourliere M, Goeser T, Marcellin P, Sanchez-Tapias J, Sarrazin C, Harvey J, Brass C, Albrecht J. Peginterferon alfa-2b plus ribavirin for treatment of chronic hepatitis $\mathrm{C}$ in previously untreated patients infected with HCV genotypes 2 or 3. J Hepatol. 2004 Jun; 40(6):993-9.

28. Zeuzem S, Rodrguez-Torres M, Rajender Reddy K, Marcellin P, Diago M, et al. (2012) Optimized threshold for serum HCV RNA to predict treatment outcomes in Hepatitis $C$ patients receiving peginterferon alfa- $2 \mathrm{a} /$ ribavirin or in population with recurrent $\mathrm{HCV}$ genotype 1 infection after living donor liver transplantation. $\mathrm{J}$ Viral Hepat2012; 19: 766-774. 